\title{
Soy Mandala: Arte, Design e iniciativas sociais
}

\section{Soy Mandala: Art, Design and social initiatives}

\author{
Carlos Eduardo Félix da Costa, PUC-Rio \\ cadu@puc-rio.br
}

\section{Resumo}

Este artigo apresenta reflexões sobre o projeto Soy Mandala, desenvolvido durante residência artística de longa duração, em parceria com a Fundação InSite, na cidade do México. São apresentados o processo de criação da obra em diálogo com conceitos e imagens que pensam a cidade, a diluição da autoria e a arte e o design como meios de manutenção e estabelecimento de elos.

Palavras-chave: Coparticipação, Artesanias, Mandala

\begin{abstract}
This paper presents reflections on the Soy Mandala project, developed during a long-term artistic residency, in partnership with the InSite Foundation in Mexico City. The creation process is presented in dialogue with concepts and images that contemplate the idea of city, dilution of authorship and art and design as means for maintaining and establishing bonds.
\end{abstract}

Keywords: Coparticipation, Handicrafts, Mandala 


\section{Introdução}

Arte e Design designam mais um lugar de instabilidade do que uma tendência ou movimento, tornando as premissas de sua ontologia uma área especulativa, ao mesmo tempo em que nada nova. Do fim do século XIX com Ruskin \& Moris, passando pelo Construtivismo Russo, de Stil a Bauhaus, até os laboratórios interdisciplinares nas universidades, o desejo de integração das áreas criativas é latente. Logo adotar o termo limiar parece adequado nesta reflexão, indicando o terreno movediço que ora atravessamos. Estamos na borda da realização poética com a da produção de uma cultura de massa. Sobre isso, recai a enorme responsabilidade de gestar as esferas imuno-simbólicas que permitirão a integração política, social, tecnológica e ambiental de visões de mundo, que nesse momento histórico, estão comprometidas mais com a produtividade e o espetáculo, do que com a constituição holística e transcendente da coletividade.

Sabemos que já nos distanciamos do utilitarismo do artefato e da tradição decorativa do Design, bem como também nos afastamos dos maneirismos de linguagem e do escapismo formal da Arte. Há, portanto, uma responsabilidade quanto ao planejamento de um futuro possível. Esse é o chamamento integrativo que a manipulação dos materiais para a tomada de formas nos clama. Assim, neste artigo se descreve uma tentativa desta aproximação, a partir da apresentação do projeto Soy Mandala, desenvolvido na cidade do México em parceria com a Fundação InSite. Para tanto, iremos estabelecer uma breve cronologia do programa, apresentar suas bases conceituais e descrever o desenvolvimento da peça em diálogo com imagens e autores engajados em pensar o meio urbano, a diluição de autorias e meios de criação colaborativa como forma de estabelecimento de vínculos.

Desde a sua criação em 1992 no particular untopos entre Estados Unidos e México, suas peças contribuíram para definir as práticas situacionais e de coparticipação presentes no léxico das ações definidas como Arte Pública. Um olhar para a história do InSite promove a contemplação de mais de 150 projetos, cuja vinculação retroalimentou a arte contemporânea e serviu como rito de passagem introspectivo para muitos de seus participantes. Francis Alÿs, Rosangêla Rennó, Silvia Gruner, Mark Bradford, dentre muitos outros, negociaram espaço citadino, fluxos de empatia grupal e rituais cotidianos em diálogo com suas poéticas pessoais. A partir de 2014, após uma pausa de quase 10 anos, o projeto abandonou o tema macropolítico de migração e fronteiras sobretudo pela dificuldade de se trabalhar entre Tijuana e San Diego após o 11 de Setembro - e inaugurou uma sede no bairro de Santa Maria la Ribeira, na capital mexicana. O espaço ficou conhecido como Casa Gallina. Dentre os diversos projetos já apoiados pela plataforma, um que sintetizou o programa ocorreu em agosto de 2005, quando um homem-bala foi atirado pela fronteira com seu passaporte no bolso, durante um desfile circense. Esse foi o ápice da obra "Um voo para o vazio", que Javier Téllez realizou onde famílias, que vivem divididas entre os dois países fazem picnics, passando tacos e refrescos entre a cerca. 


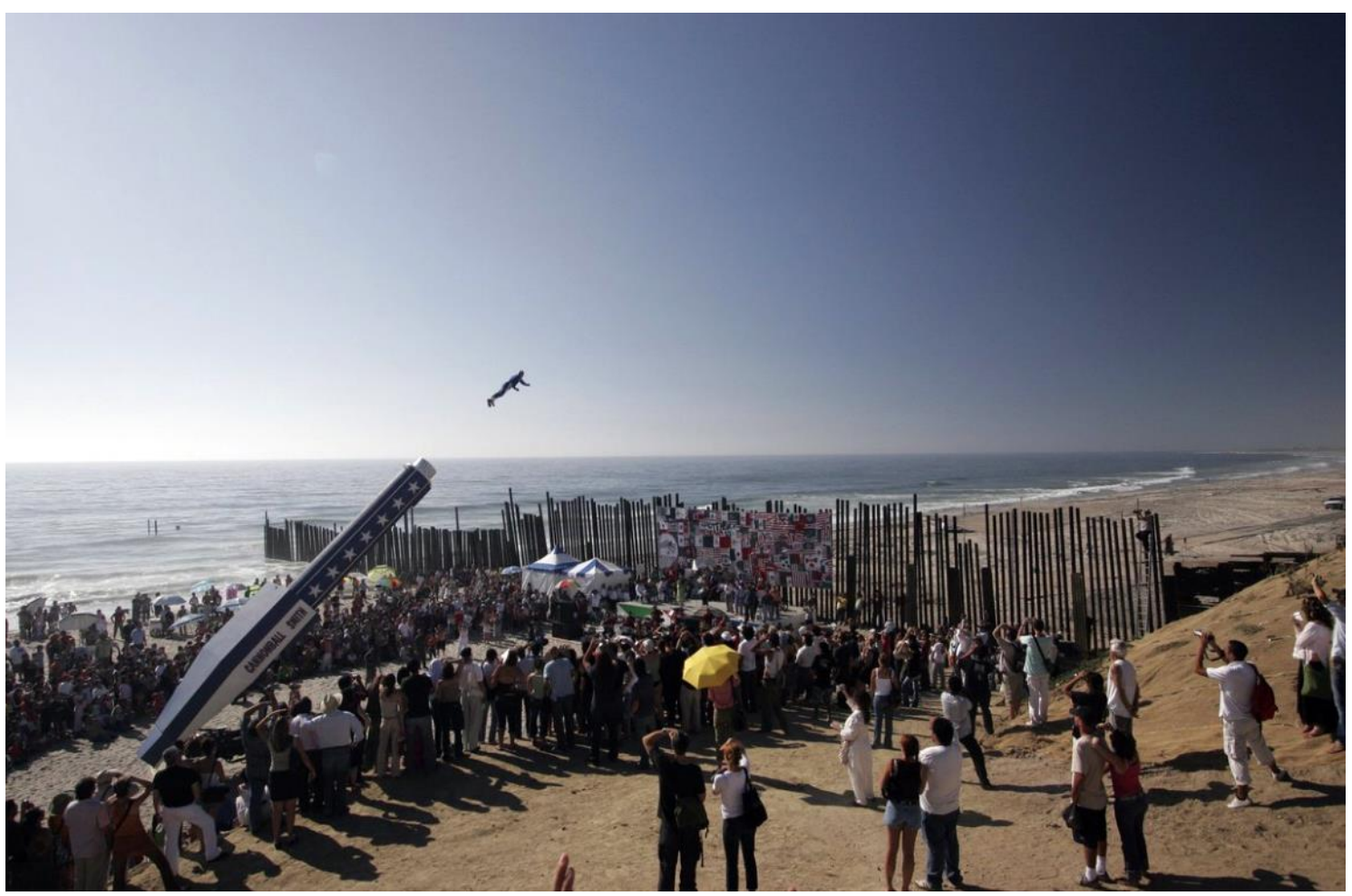

Figura 1: Javier Téllez, “Um voo para o vazio”, 2005. Fonte, https://twitter.com/art2030org/status/958014379253002241

Na segunda metade do século XIX, a Cidade do México cresce nas cercanias do centro. Terrenos cedidos pela família Flores são utilizados para a construção de parques, mercados e praças. Edificações que pudessem atrair a burguesia, já incomodada com a saturação das áreas históricas. Num destes bulevares, durante o centenário de independência, é remontado o pavilhão mexicano da Exposição Internacional de Nova Orleans (dezembro de 1884 a maio de 1885), conhecido como Kiosco Morisco. Sua arquitetura de ferro e vidro em estilo franco-árabe tornouse o epicentro de Santa Maria. Ao lado se encontra o Museu de Geologia da Universidade Autónoma do México e, a poucas quadras deste, o Museu Universitário del Chopo. No entanto, nos anos 30 e 40, o desenvolvimento desloca-se para regiões como San Rafael, Roma e Condessa, iniciando o translado da classe intelectual e econômica. Os edifícios e mansões coloniais, ou são recortados, convertendo-se em cortiços, ou demolidos para a construção de condomínios. Após o terremoto de 1985, o crescimento populacional devido a migração de desabrigados para imóveis desocupados, transformou definitivamente o bairro numa colônia popular.

Fatores como sua localização central, baixos alugueis, oferta de espaço residencial em moldes generosos, proximidade com unidades universitárias e o passado aristocrático, atraíram também uma população jovem, buscando alternativas as zonas de classe média. Esse componente ofereceu ao lugar uma textura plural, resultando em novos negócios e vida cultural, além da convivência entre comércios familiares e moradores de baixa renda. A porosidade social, ausência de gentrificação e diálogo entre passado e futuro foram as determinantes que levaram a fundação a se estabelecer num casarão da região. O imóvel foi completamente reformado, e nele conviveram 
por 5 anos um horto, classes de culinária e economia doméstica e informática para a terceira idade, um centro de organização de relatos do bairro, uma residência artística, e toda a natureza de projetos que possibilitassem o surgimento de elos criativos horizontais com a população, tendo como elementos centrais o conceito de lar e hospitalidade. Encontramos nessa decisão uma postura engajada, imbuída de uma potência edificadora da Arte como força social, econômica e psicológica de transformação, sem desprivilegiar outras naturezas de saberes constituídos no cotidiano, livres de uma base intelectual considerada elevada. Os artistas não estavam numa posição "emissária" de conhecimento, eram apenas parte da constelação de pesquisa da casa, interessada mais na corrosão de estruturas de poder do que em produzir obras de arte. $\mathrm{O}$ foco era a comunidade e não seu extrativismo.

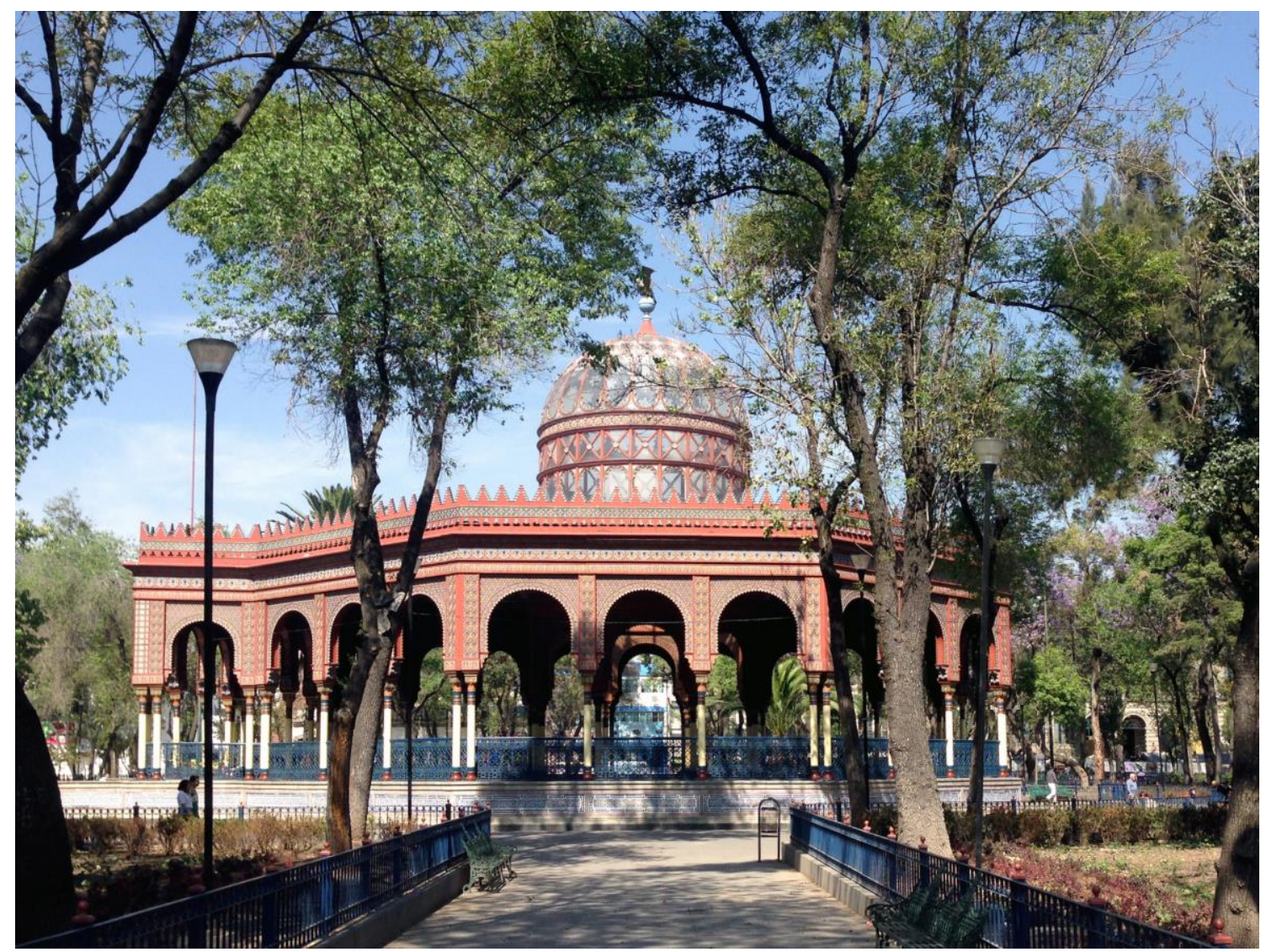

Figura 2: Kisco Morisco, Santa Maria la Ribeira. Fonte: o autor.

Um bairro é um domínio de sociabilidade, uma porção familiar do espaço urbano em que o indivíduo, em maior ou menor grau, se vê reconhecido. Um espaço público em progressiva privatização. Área de intimidade ampliada, em que a partir do habitar, implementam-se bases para negociação com usuários pertencentes ao ambiente, ou de outros contextos urbanos. É uma zona de aprendizagem, onde convenções coletivas tácitas são implementadas através de códigos de conduta. Para o InSite, a coparticipação artística seria um dos modos possíveis de se manter a sustentabilidade do contrato social. Uma prática restaurativa marcada pela aceitação da fragilidade e pela impossibilidade total de consolidação, mas que oferece o intercâmbio de perspectivas, necessário para o reforço dos laços comunitários. A diversidade é exercitada em 
manifestações desta natureza, e capaz de construir seu braço político, propondo mudanças nos espaços de criação partilhados, antes de se darem na realidade.

Portanto, as residências iniciam-se por uma imersão: os convidados não devem chegar com ideias pré-estabelecidas, apenas percorrer, na companhia de curadores e antropólogos, os dezoito quarteirões previamente mapeados. Durante estas incursões são atualizados das atividades desenvolvidas na área: petshops, cabeleireiros, bares, oficinas mecânicas, perímetro de gangues, residentes ilustres e tendas de curandeiros. Tudo que está listado é partilhado. Um sistema criativo necessita da presença de informação alheia, que aparentemente irrelevante, pode se tornar crucial na formulação de problemas. Essa é a estratégia da plataforma para criar uma ligeira gama de opções e pontos de partida, que devem florescer pela regra do convívio.

O papel dos artistas em residência é de frequentar lugares, sentir afinidades, e, após um período de incubação, tentar aproximações. Consentir a deriva como companheira é fundamental nesta fase de prospecção. Uma disponibilidade branda, a partir da desaceleração, deve ser perseguida para um descolamento do tempo íntimo, do tempo do mundo. A ambição é a de introduzir uma ciência caseira, de métodos próprios, que proporcione a passagem da condição espectadora para uma participativa. Transformar o vivido numa narrativa é confiar no prumo que habita o acaso, como apontado pelo mestre espanhol:

E, por não podermos parar, nada nos acontece. A experiência, a possibilidade de que algo nos aconteça ou nos toque, requer um gesto de interrupção, um gesto que é quase impossível nos tempos que correm: requer parar para pensar, parar para olhar, parar para escutar, pensar mais devagar, olhar mais devagar, e escutar mais devagar; parar para sentir, sentir mais devagar, demorar-se nos detalhes, suspender a opinião, suspender o juízo, suspender a vontade, suspender o automatismo da ação, cultivar a atenção e a delicadeza, abrir os olhos e os ouvidos, falar sobre o que nos acontece, aprender a lentidão, escutar aos outros, cultivar a arte do encontro, calar muito, ter paciência e dar-se tempo e espaço. (BONDÍA, 2002, p. 24)

Habitamos um estado de desatenção, que impede o tédio ou a contemplação. A condição pósmoderna nos pressiona à construção de um projeto existencial em negociação com uma realidade econômica compulsória, gerando contradições de valores quase irreconciliáveis entre si. Marc Augé (2010) aponta, dentre outros sintomas daquilo que batiza de sobremodernidade, a mobilidade como um dos paradoxos que rege nosso tempo. Ela se exprime nos movimentos de população, na comunicação instantânea e na circulação de produtos, imagens e informações. Não há mais interditos ou tabus que impeçam essa marcha em rede. Tanto trânsito nos leva a questionar uma definição cara ao InSite, e sempre presente em suas propostas: o conceito de fronteira, noção que, desde a aparição da linguagem, se encontra no núcleo da atividade simbólica, empregada para designar o mundo através de categorias opostas e complementares. Compartimentamos o espaço, classificando-o com a intensão de facilitar a navegação pelo mesmo.

A fronteira impõe a necessidade de aprender para compreender. Este permanente estado de instrução quanto a alteridade mantém as raias do percurso em redesenho. Nossa compreensão e deslocamento $n a$ e $d a$ se dão através da permanência nesta interseção. É isso que nos ensina os conhecimentos científico e artístico, por exemplo. Eles nunca são absolutos e estão sempre 
avançando e retrocedendo em dinâmicas que demonstram, muitas vezes, que as conquistas se dão em proporção ao abandono.

A mobilidade nos permite ponderar quanto ao turismo e a etnografia, correntes provisórias e intercambiáveis dos processos de construção de significado. Ambas são condições de deslocamentos temporários, mas que apresentam distinções em suas causas e consequências. Enquanto o turista reside nas superfícies e possui um prazo de validade breve, o etnólogo é o da observação solitária e monótona, e regressa apenas quando satisfeito. O turista não é aceito pelo local e consome e coleciona visitas. Já o etnólogo altera o ambiente que circunda pela duração da estadia, e por um exame inquisidor, confere caráter reflexivo à viagem após o retorno.

Em "O Tratado de Nomadologia, A Máquina de Guerra", Deleuze \& Guattari (1994) criam uma distinção estratégica de deslocamento entre o jogo ocidental de xadrez e seu equivalente oriental, o go, ilustrando os embates entre o Nomadismo e o Estado sedentário. Aliada à consequente diferenciação entre espaços lisos e estriados percebemos o exercício da criação como uma atividade fronteiriça entre tais territórios e, portanto, dotada de estratégias que ora visam a conservação e o acúmulo de conhecimento, ora o esquecimento e até a auto-sabotagem, para sua própria manutenção.

O xadrez é considerado um jogo de Estado. A codificação do movimento de cada peça the atribui propriedades que determinam importância simbólica. Há logo de início um sujeito enunciado, dotado de um poder relativo, que toma decisões de maior ou menor relevância para o todo. Já as pastilhas anônimas, os peões do go, são simplesmente unidades aritméticas coletivas ou de terceira pessoa. Estas peças são um agenciamento maquínico não subjetivado, sem propriedades intrínsecas, que levam em consideração apenas a situação em si. No xadrez temos uma estrutura militar organizada, com fronte, retaguarda e manobras institucionalizadas. Deve-se ocupar o máximo de casas com um mínimo de peças. Já no go há uma lógica de guerrilha por trás; não há linha de combate definida, é essencial manter a possibilidade de surgir a qualquer momento.

No espaço estriado, os itinerários têm a tendência de subordinação aos pontos. No liso nômade, os pontos estão subordinados ao trajeto, uma vez que este deslocamento não será simplesmente o cumprimento de uma extensão, mas a negociação com os sintomas locais surgidos durante a ação. Tanto no liso como no estriado há paradas e trajetos, mas no deslocamento nômade é o trajeto que provoca a parada. No espaço liso, a direção é um vetor e não uma dimensão métrica a se cobrir. É mais de afetos que de propriedades, intensiva mais do que extensiva. De todo o devir. Já o espaço estriado seria aquele que se ocupa para metrificar, organizar e esquadrinhar; para transformar espaço em distrito, numa estratégia de assentamento.

A tensão entre estes limites foi um dos anseios perseguidos na realização do projeto, conjugando ambiguidade e rigor, não desejando expor contradições, mas encontrando-se no interior de um drama saudável. Algo que ora reforça, ora questiona um posicionamento, mantendo o pensamento como um estrangeiro alerta entre fronteiras. Estar "entre", na verdade, é a condição que propicia evoluir no interior de uma linguagem; porque assim como o espaço liso necessita do estriado para proliferar, e o estriado tende a surgir do interior da lisura, o criador se baseia em sensações intuitivas para alimentar decisões exatas. Nunca se deve priorizar o mais fácil ou o que 
demonstre maior eficiência, mas confiar no risco e naquilo que o impulsiona a seguir adiante por ser obscuro e atraente. De um lado o mundo inteligível, aparente; do outro uma linguagem amorfa e latente, aguardando por manipulação. Devemos borrar, exercer superposições, conjunções, trocas entre dados da racionalidade e da imaginabilidade. A criação nasce desta natureza de atritos.

\section{Aproximações e Entrelaçamentos}

Após algumas inserções frustradas num pequeno negócio de comida e numa fundação para cegos, onde pretendia trabalhar como voluntário, por desespero e quase aleatoriedade o pesquisador matriculou-se numa aula de baile para idosos, e após uma detalhada entrevista, foi aceito com desconfiança e ressalvas. Duas vezes por semanas um grupo de senhoras entre $58 \mathrm{e}$ 89 anos reunia-se na Casa de Cultura. Ali desenvolviam coreografias sobre ritmos latinos como danzon, chá-chá-chá, cúmbia, salsa e bolero. A liderança era de maestra Juanita, de 62 anos, que passou infância e juventude deslocando-se pelo país a bordo de uma caravana férrea, composta por operários responsáveis pela manutenção da rede federal. Sua mãe possuía um vagão restaurante, que também funcionava como mercearia e lavanderia. Juanita conheceu praticamente todo o México até se casar e decidir viver na capital. Herdou a classe após o falecimento da antiga mentora, por ter o hábito de anotar os movimentos em cadernos.

Aos poucos o grupo mostrou-se bastante organizado e nada amador. Las chicas de ayer, hoy y siempre, como eram conhecidas as abuelitas, apresentavam-se em eventos e até comemorações cívicas. Passado o momento de estranhamento, em que o exotismo compunha uma zona de interesse mútuo, estabeleceu-se a confiança. Chás e voltinhas na praça passaram a compor um campo ampliado de convivência e investigação. Cada incursão ao mundo destas senhoras abria suas fragilidades, melancólicas histórias de vida e alegrias. Uma delas era especialista em medicina floral; outra dona de uma tenda de abarrotes (secos e molhados). Uma atravessava conflitos com a irmã deficiente mental; a segunda estudava para ser esteticista; a terceira complementava o orçamento vendendo produtos brasileiros da Natura. Mas além da dança havia algo a mais que as unia. Todas crochetavam e se reuniam em grupos menores, para a troca de gabaritos e apreciação de trabalhos.

Durante a residência junto ao InSite, que durou 3 anos (contando produção e pós-produção), o pesquisador foi paralelamente convidado à integrar outro projeto, na cidade de Nowy Sacz, interior da Cracóvia. Dentre outras obras, uma peça criada com uma artesã local contribuiu significativamente para o projeto no México. Eva Szpila era conhecida pelas habilidades em tricô, crochê e bordado. Uma senhora na casa dos 50 anos, que se tranquilizava com o artesanato. A prática surgiu para se ocupar durante madrugadas insones. Entre seus interesses, estava o desafio de ensinar algumas técnicas a Malgorzata Szpila, sua filha.

Assim, elaborou-se um meio de transmitir esses conhecimentos utilizando uma escultura performativa, baseada em dois cilindros, como mangas agigantadas de suéter do tamanho de mãe e filha, que possuíam início e fim interligados por metros de fio. Colocou-se cada casulo num extremo da galeria para que elas não tivessem contato direto entre si, exceto pelo trabalho concomitante. A linha que ligava as estruturas corria pela área expositiva desenhando o espaço. 
Para a manutenção dos ciclos, precisavam subtrair da estrutura gêmea em poder da outra, ao mesmo tempo que ceder. Usurparam e ofertaram ciclicamente por três horas, todos os dias durante meses, num misto de passagem de conhecimento, ritual e obra artística. Deste modo, a primeira mulher (Eva) instruiu sua cria na técnica de invocar labirintos por passes de mão e linha. Estaria ela já intuindo na prole a herança das noites em claro? Após o período, Malgorzata era quase tão habilidosa quanto sua genitora. Dormia melhor também, dizem. Clotho, umas das três Moiras, manipuladora da Roda da Fortuna e detentora do destino de mortais e deuses, batizou a obra.

Esta breve pausa num projeto para a incursão em outro, mas que se contaminaram mutuamente, nos rememora um pouco a postura de Argan (1993) em "A História na Metodologia do Projeto", quando assume que o ato de projetar ocorre a partir da crítica de algo já iniciado, isto é, de um processo de ações e reflexões sobre o materializado. O projeto, em sua concepção é contínuo: logo, designers, artistas, arquitetos e engenheiros usam imaginação, pesquisa e criatividade antecipando tendências e problemas, passando por situações de testes, erros e análises, que inauguram ciclos de redesenho na história daquele objeto. Para o autor, todo projeto é uma crítica de algo existente, sendo assim, passível de atualização.

No entanto, quando projetamos há uma grande carga de idealização, pressupondo parâmetros de desempenho quase inatingíveis. Ainda existe a vinculação a uma lógica modernista, em que um bom trabalho é a realização de uma plenitude - nada pode ser adicionado, ou subtraído. Porém devemos compreender os processos projetivos como um enredamento de dinâmicas com velocidades distintas é aceitar que a invenção é um veículo de síntese, que dinamiza, integra e se adapta ao contexto, sem a intimidadora e frustrante ambição de encerrar um problema, mas sim visitar e revisitar questões. Adotar uma postura aberta, menos obcecada pelo sucesso, pode colaborar para a conciliação entre afeto e pragmatismo, que tanto tem representado fonte de encabulamento para aqueles das áreas criativas.

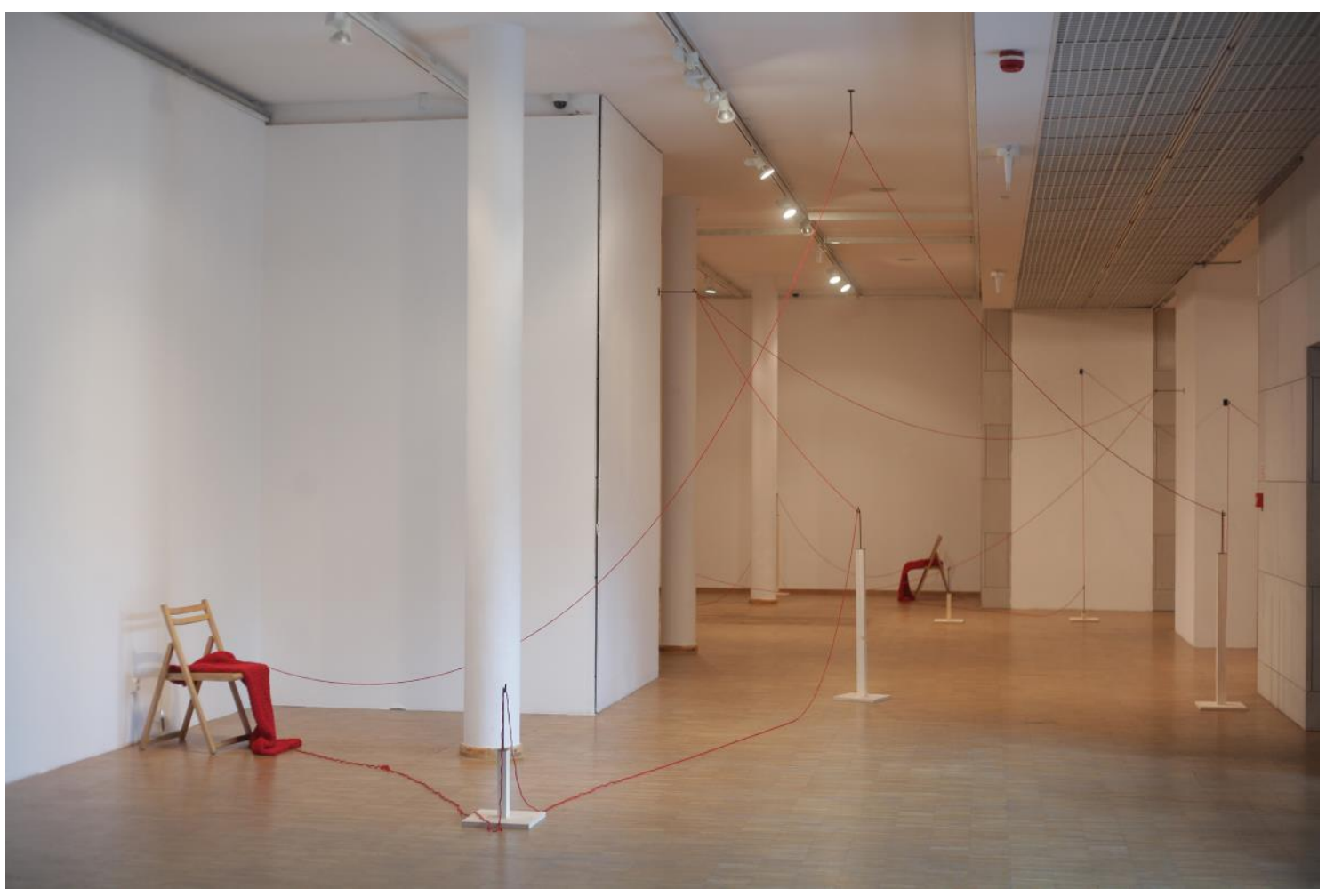


Figura 3: Chotho, 2015. Instalação constitutiva da mostra "It's Gonna Rain" - BWA Sokol (Nowy Sacz). Fonte: o autor.

A partir da experiência polonesa, estudamos e compreendemos melhor os pontos, cores e padrões aplicados nos bordados pelas senhoras em Santa Maria, nos aprofundando quanto ao artesanato e em como aproveitar suas técnicas no trabalho do México. Encontrou-se um paralelismo entre as duas atividades de grupo das senhoras. Estávamos diante de manifestações complementares de suas feminilidades, mas que podiam ser encaradas como coreografias: uma dos "pequenos" e outra dos "grandes" músculos. Tecer e dançar eram práticas mais próximas do que se supunha. Surgia a possibilidade de encriptar a memória coletiva numa partitura de baile fiada. Mas faltava um último elemento simbólico temporal a ser articulado.

No oriente há estruturas recursivas constituídas do recheio de ampulhetas. Denominamos esses labirintos arenosos de mandalas. Arquiteturas celestes, construídas com paciência, favorecem a incorporação de valores transcendentes, adquiridos com a sabedoria silenciosa da abnegação. Sua fisicalidade deve ser superada pelo desmanche quando concluídas. Artesanatos têxteis costumam integrar a mesma expansão circular e não raro, são também percebidos como rituais domésticos mínimos.

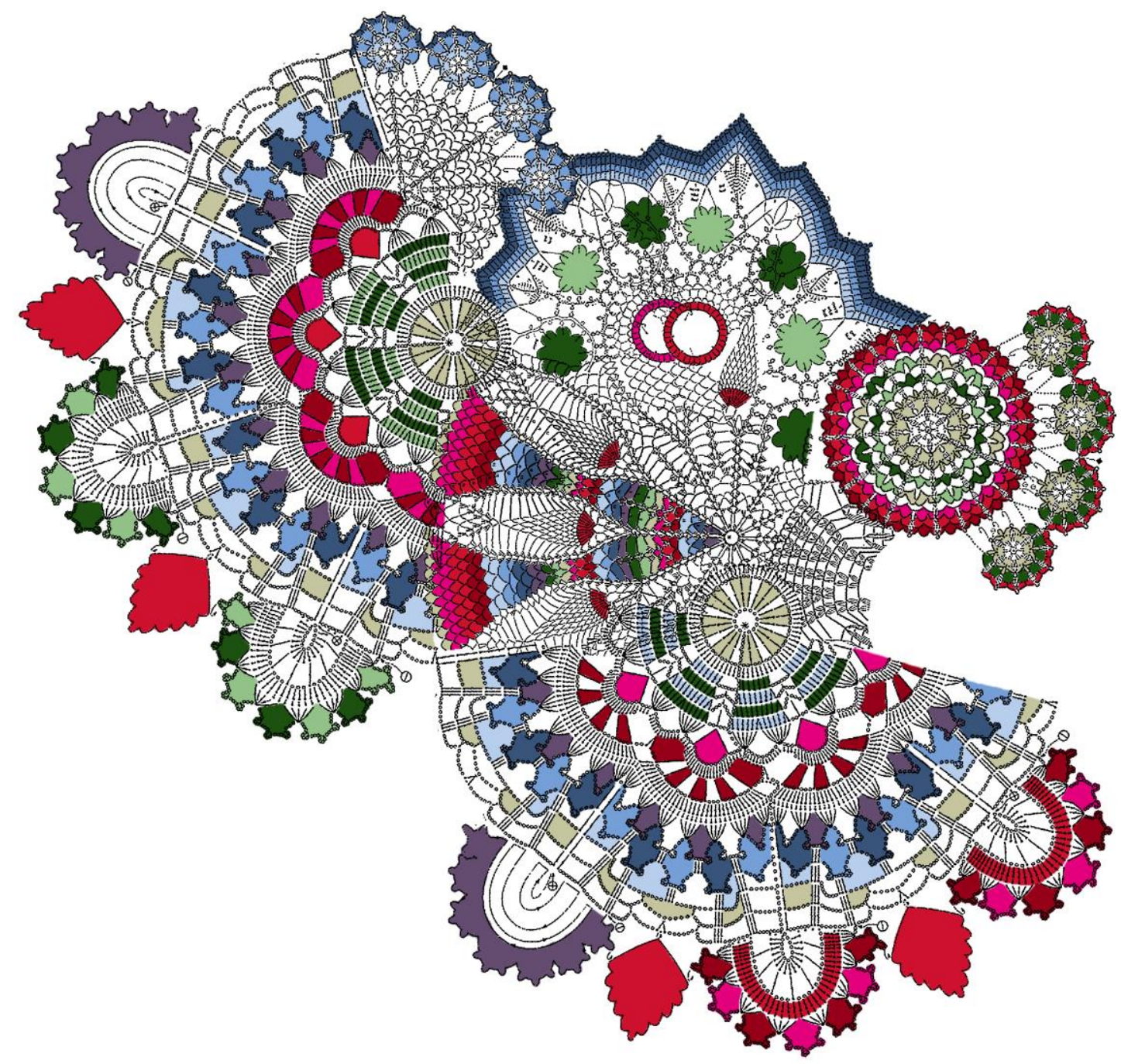


Figura 4: Desenho final da mandala desenvolvida em parceria com senhoras. Fonte: o autor.

Após meses de pesquisa - estudos de cores, meios de como encontrar equivalências entre movimentos de crochê e passos de dança e, principalmente, convencendo as senhoras da importância da desconstrução do que fosse produzido - chegou-se a um desenho inspirado na planta baixa do símbolo arquitetônico do bairro, o já citado Kiosco Morisco, como base para uma mandala. Porém, não havia como emprega-las na execução da peça. Entre seus afazeres domésticos, as práticas de baile e o conhecimento limitado de técnicas de tecelagem, ficou claro que o processo era para especialistas. Iniciou-se essa busca visitando um pueblo à duas horas e meia da capital. Gualupita é famosa pelo tingimento de fibras e o trabalho em tear de cintura, pregos e pedal. Lá, revelou-se outro importante interlocutor, Don Efren, um senhor de 67 anos pertencente a uma família que, por gerações, dedica-se a executar tecidos comemorativos sob encomenda. Os manteles, como são conhecidos, levam anos para ficar prontos e incorporam dúzias de tipos de fios, conjugando os mais belos padrões tradicionais mexicanos com os de origem europeia. O maestro contribuiu com conselhos quanto a espessura dos barramentos, ordenações de cores e meios de realizar emendas que se desfiassem com facilidade. Forneceu também estimativas de metragem e tempo de execução.

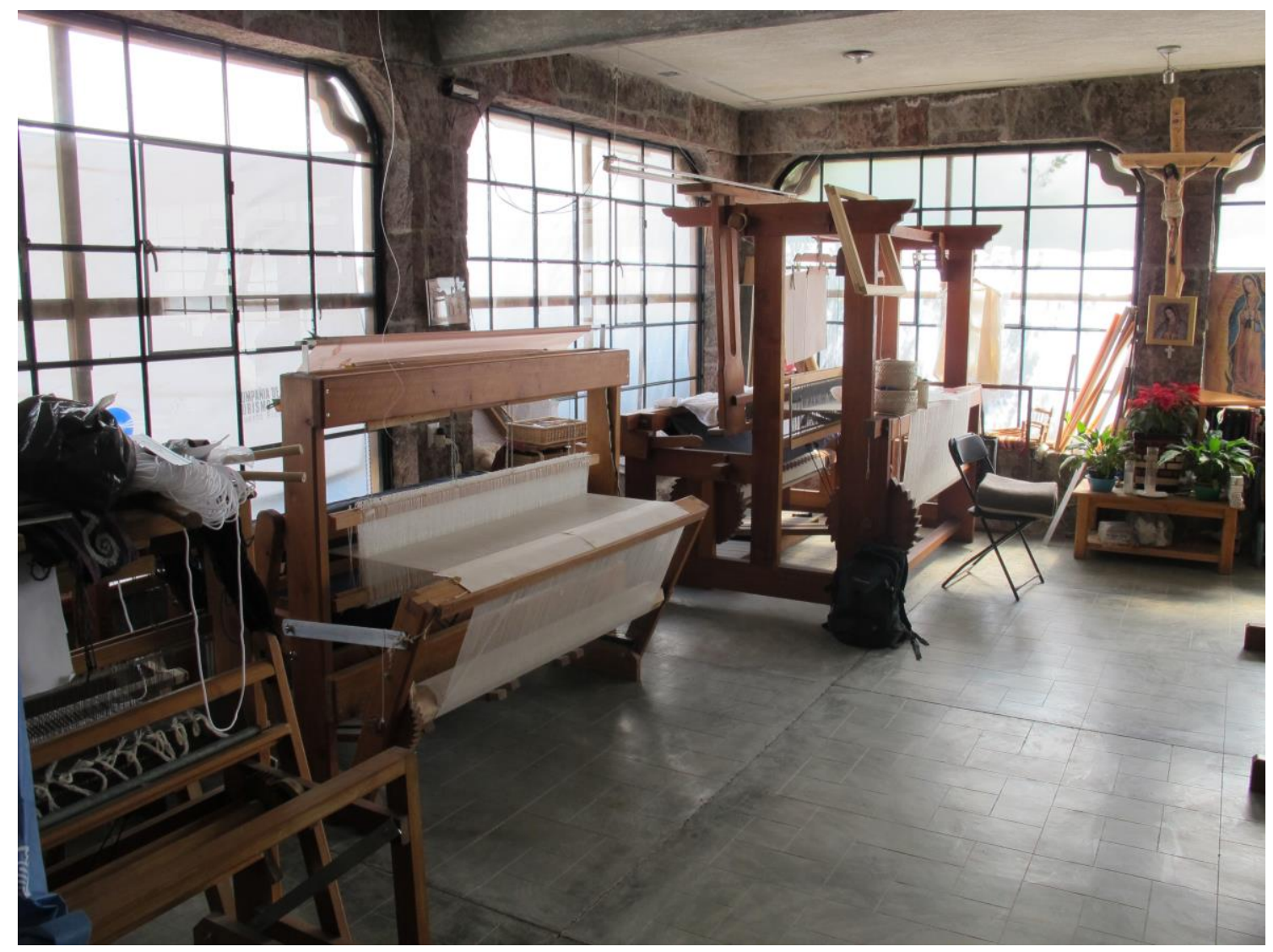

Figura 5:Atelier de Don Efren em Gualupita. Fonte: o autor.

No entanto, o artesão não produziria a peça. Morava longe, trabalhava sozinho e num ritmo lento. Assim, se estabeleceu parceria com Esperanza, uma das fundadoras da Tejiendo otro 
Mundo, que confeccionava cobertores para a população de rua. O princípio da organização é simples: os voluntários tecem superfícies de 20 x $20 \mathrm{~cm}$ e os enviam à sede. De lá outros voluntários fazem as emendas dos quadros e, através de associações de assistência, os distribuem aos necessitados.

Esperanza reuniu uma equipe feminina, que iniciou os trabalhos. Mulheres jovens prestavam uma homenagem a anciãs num gesto de respeito a suas histórias. Diariamente o grupo tecia por horas uma estrutura de 6 por 7 metros. Tarefa por si complexa, mas que feita para ser desmanchada ao final, demonstrou ser uma verdadeira façanha da engenharia dos entrelaçamentos. A produção tomou 7 meses e durante esse período, as senhoras ensaiavam. Em parceria com Esthel Vogrig, bailarina e coreógrafa, desenvolveu-se uma rotina baseada em passos de outros números do grupo. Las chicas eram caprichosas, pouco dispostas a mudar sua maneira de bailar em função da peça, o que fazia sentido, pois haviam encontrado ritmos perfeitamente adequados a sua idade. O projeto deveria se harmonizar a elas, não o inverso.

\section{Baile e Desaparecimento}

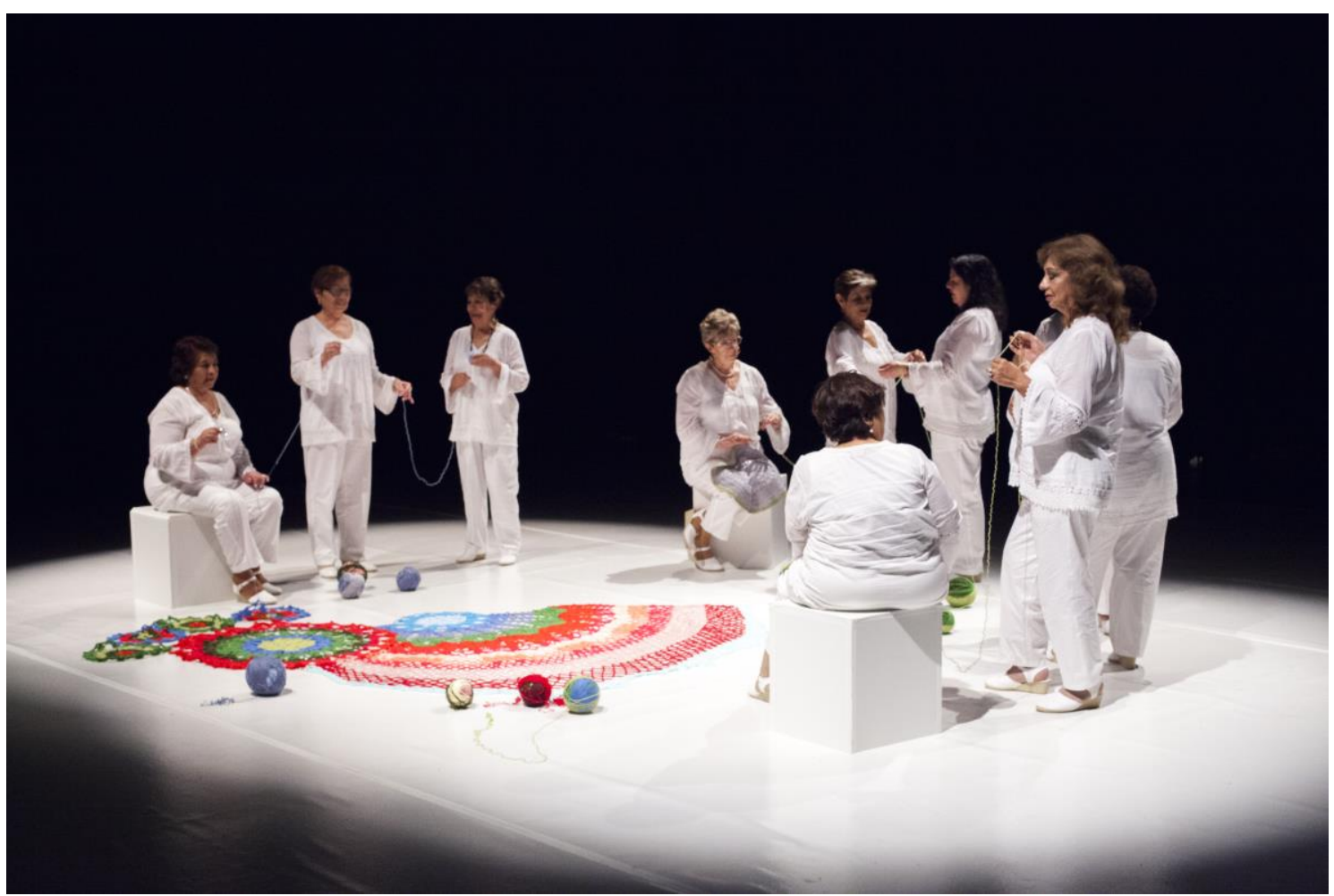

Figura 6: Registro da desconstrução da mandala. Fonte: o autor.

Dois anos após a primeira visita ao México, tudo estava pronto para o cerimonial sobre a vida e a finitude. Até aquele momento mais de 40 pessoas já haviam se envolvido com o projeto; curadores, produtores, antropólogos, dançarinos, artesãos, fotógrafos, designers, sonoplastas, 
músicos e tantos outros colaboradores representavam os milhares de gestos que construíram uma rede de afetos e habilidades, sem os quais seria impossível avançar. No final de 2016 estavam todos reunidos no teatro Julio Castillo, inaugurado em maio de 1957 com "Bodas de Sangue" e "A Casa de Bernarda Alba", de García Lorca. No mesmo palco, 11 senhoras anônimas desfiaram durante dois dias de filmagem o tempo de trabalho de todos.

Seria extremamente longa a descrição de toda a cadeia de decisões simbólicas e logísticas que permearam estas 48 horas. No entanto, é fácil imaginar o nível de envolvimento de todos para abrir mão de um longo processo artesanal em prol de uma ausência. Por mais contentes e orgulhosos de suas contribuições para o projeto, os profissionais desta teia transdisciplinar compreendiam que o fruto de suas dedicações iria macular-se e desaparecer. Como num ritual invertido, o totem construído anteriormente desapareceria, aportando a geografia-mundo de uma grafia imaginal, de mundos ainda em insinuação. No entanto, é importante salientar que ainda há duas pequenas réplicas da mandala, exibidas em exposições junto ao filme resultante das gravações.

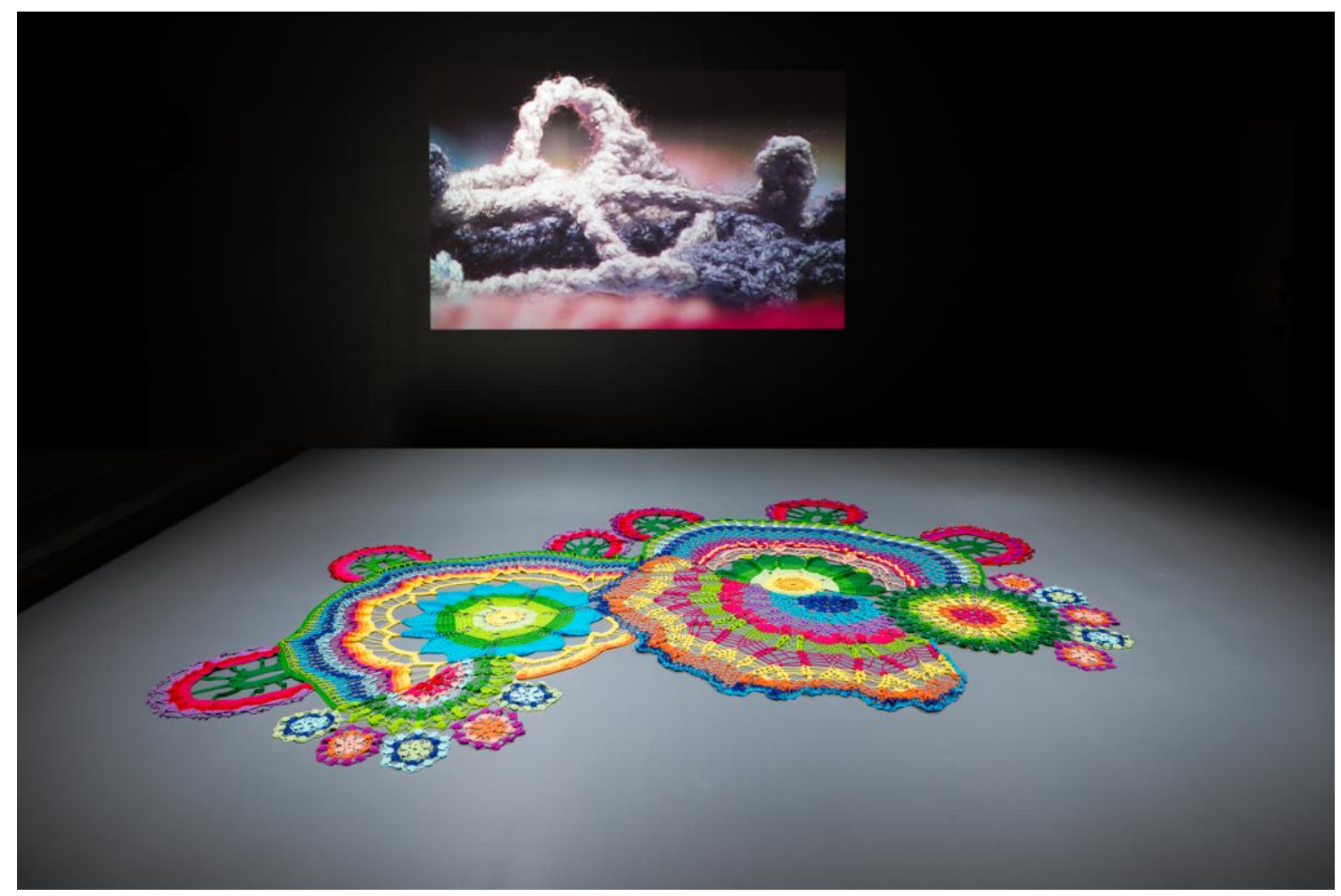

Figura 7: Vista da instalação “Soy Mandala”. Fundação Jumex, cidade do México, 2018. Fonte: o autor.

Ficou evidente que há uma área de intersecção na qual contextos culturais, diferenças etárias e outros meios de distinção podem ser abrandados. Uma vez que percebamos o outro como coprotagonista na construção do enredo, e que consigamos tolerar o indeterminado coletivo até que se insinuem direções, a fisicalidade da matéria e seu traumático desaparecimento serão encarados com tranquilidade diante da inestimável identificação e exercício de convivência. Analisando toda a experiência retrospectivamente, encontram-se semelhanças entre o processo atravessado em caravana e aquilo que Nietzsche (1994) chamou de "as três metamorfoses do 
espírito". Na primeira, aceita-se camelo. Quando, para a dura travessia, o viajante transforma sua alma em besta de carga e acumula provações que curvem os joelhos na esperança de açoitar o ego. A tenacidade é testada com abnegação diante das violências do mundo. Consciente mais de suas limitações do que de suas virtudes, atravessa a segunda metamorfose. Percebe-se leão, quando não mais quer seguir nenhum senhor e sim exercer seu desejo sem temor. Quando quer conquistar o direito sagrado ao não. A fera se faz necessária para rapinar antigos valores e abrir a escolha, mesmo diante do dever. Porém, o que pode a criança diante do leão? Por ser inocência e esquecimento, o complementa. Da agressividade à doçura, oferecendo o entendimento de que o novo nasce de passos tolos e que manter o estado infante é o único meio de se jogar o jogo da criação. É esta a terceira e última metamorfose do espírito.

Parece que é no ocaso da existência que esta reconciliação se dá. Quando não se quer mais do que se tem, mas que se seja restituído do que foi levado. Pois nas ausências residem os recomeços. É sabido que a morte deve aguardar a última dança do guerreiro. Se desenhou a vida de intensos eventos, a coreografia será longa. A morte assistirá com prazer antes de conduzi-lo. Sua companhia em todos os momentos da existência é para este latente alerta: para lembrarmo-nos de coreografar no limite do impensável, do gozo, da dor e da doçura. Não para anunciar o fim. Este somos nós que damos. Revolução sem dança é como se revolução não tivesse havido.

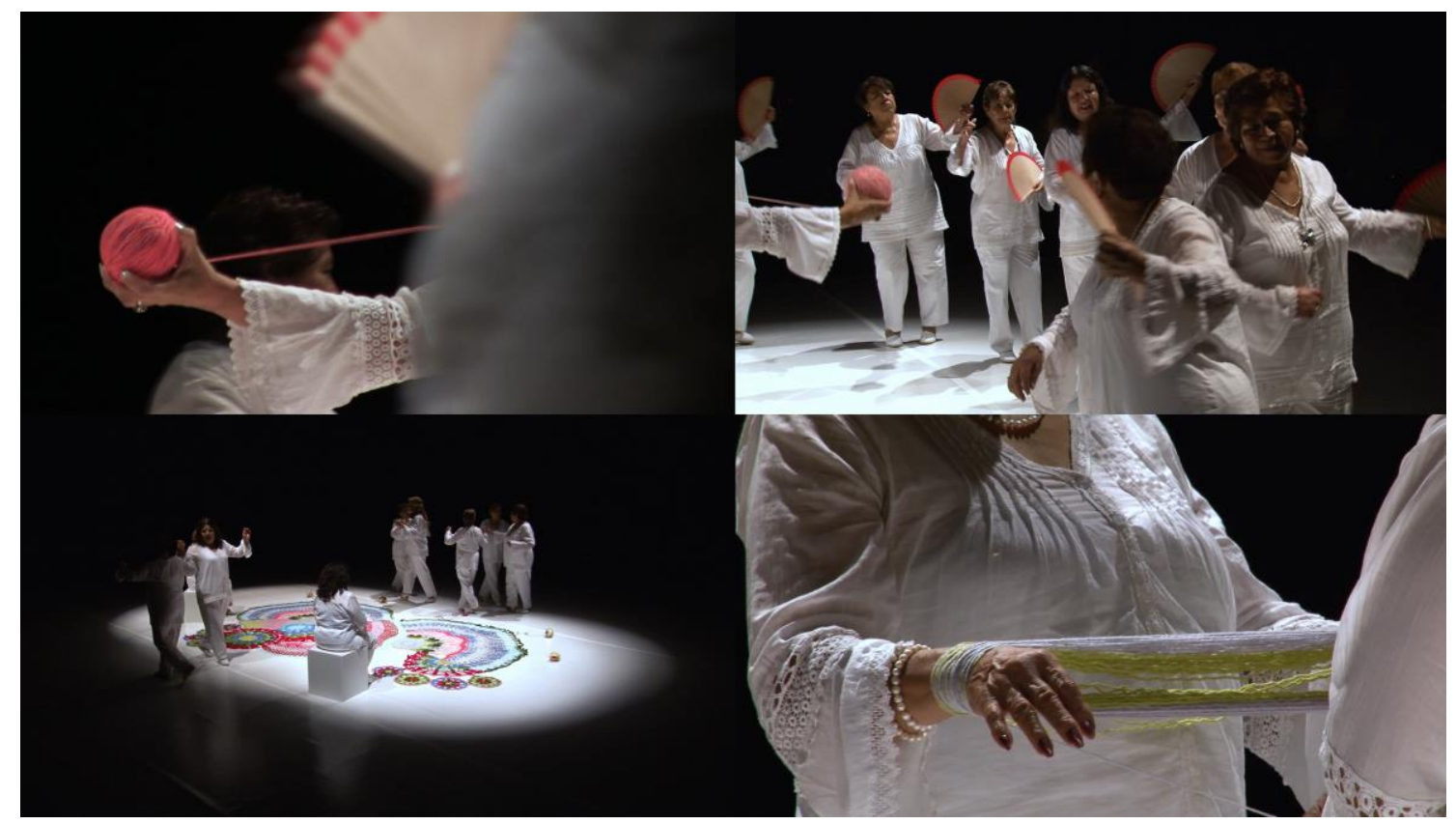

Figura 7: Frames do vídeo final de Soy Mandala. Fonte: o autor.

Sloterdijk (2016) afirma que na entrada da Academia de Platão havia um aviso saudando os geômetras e desaconselhando o ingresso daqueles que não o fossem. A despeito da aparente arrogância, os dizeres compunham um convite subliminar de reflexão sobre o que seria esse indivíduo: alguém com conhecimentos prévios numa área espacial da matemática, ou com a inteligência intuitiva de deter reminiscências anteriores à vida, da estadia num mundo de formas perfeitas? É conhecida também a presença de um segundo alerta. De que se afastassem os 
indispostos a viver casos de amor no interior do jardim dos teóricos, ou seja, aqueles que se desviam da imanência de Eros não estariam aptos ao entendimento da história das formas como um romance.

No centro dos jardins protegidos, como intui-se ser o platônico, há sempre um chafariz, os alquimistas o chamavam de fons mercurialis, Fonte de Mercúrio, ou de Hermes. O deus grego costuma conduzir a formação de contenedores, de áreas reservadas ao trabalho interior e ao cuidado. Um claustro monástico, uma câmara de meditação, a cela dos amantes, o vaso alquímico, a compota de ambrosia, todos são espaços hermeticamente selados, chancelados por Hermes. Onde a primavera se preserva é o local onde ocorre a fusão. Não apenas dos metais pelos princípios da dissolução e coagulação, mas dos corpos venéreos:

Quando duas pessoas estão fechadas nas intimidades de um caso de amor, especialmente o que é secreto, podem sentir que os sólidos em seu interior se transformam em líquidos, e os líquidos, em ar. O calor de Eros é um prazer misturado com perigo. (BLY, 1991, p. 126)

Para se viver o perigo com deleite, quanto o prazer ainda não conhece problemas, é preciso proteção. É preciso bordas e, acima de tudo, é preciso admirar como a órbita das geometrias circunscritas que emanam de seu núcleo, propiciam encontros metamórficos. Foi esta a confiança necessária para se chegar aos elos emocionais, caros a este projeto, que como eco, possibilitaram redondezas físicas temporárias. O que foi realizado com essas senhoras e toda a equipe de produção, era essa travessia do afeto pelo mundo das formas invisíveis. Aquilo que foi delicadamente cultivado no interior de cirandas protegidas com as companheiras de revolução, deveria modificar a todos, e como consequência colateral, deixar algo passageiro neste plano. A intersecção desse encontro, estava fadada a desaparecer, mas não antes sem o labor depurativo.

\section{Referências}

ARGAN, G. C. A História da Metodologia de Projeto -Revista Caramelo n.6. São Paulo: FAU/USP, 1992.

AUGÉ, M. Por uma Antropologia da Mobilidade. São Paulo: Ed. Unesp, 2010.

BLY, R. João de ferro. Rio de Janeiro: Campus, 1991.

BONDÍA, J. L. Notas sobre a experiência e o saber de experiência. Rio de Janeiro: Rev. Bras. Educ n.19, 2002.

DELEUZE, G.; GUATTARI, F. Mil Platôs - Capitalismo e Esquizofrenia, Vol. 5, tr. Peter Pál PELBART e Janice CAIAFA. São Paulo: Editora 34, 2005.

NIETZSCHE, F. W. Assim falou Zaratustra. Rio de Janeiro: Bertrand Brasil, 1994.

SLOTERDIJK, P. Esferas I: Bolhas. São Paulo: Estação Liberdade, 2016. 


\section{Carlos Eduardo Félix da Costa}

Artista plástico e professor do Departamento de Artes e Design da PUC-Rio, onde coordena o LINDA - Laboratório Interdisciplinar em Natureza, Design e Arte. Vencedor do Prêmio PIPA (2013), foi participante das Bienais do Mercosul, São Paulo, Mar Del Plata, Istambul e Coimbra, além de inúmeras mostras nacionais e internacionais. É representado pela Galeria Vermelho (SP) e Anita Schwartz (RJ). 